\title{
ORIGINAL ARTICLE \\ Perceived functional impairment and spirituality/religiosity as predictors of depression in a Sri Lankan spinal cord injury patient population
}

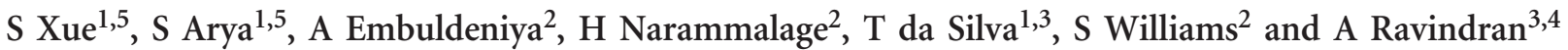

Study design: Cross-sectional, questionnaire-based study.

Objectives: To test the hypothesis that self-perceived functional impairment and religiosity/spirituality (S/R) predict depression among traumatic spinal cord injury (SCl) patients in Sri Lanka.

Setting: Ragama Rheumatology and Rehabilitation Hospital, Ragama, Sri Lanka.

Methods: The Spinal Cord Independence Measure, Benefit Through Spirituality/Religiosity Scale, Sheehan Disability Inventory and Beck Depression Inventory-II (BDI-II) were administered to 61 consenting in-patients with traumatic SCI between June and July 2014. A linear regression model on BDI-II score was developed to examine the impact of self-perceived functional impairment and $S / R$ activities on psychiatric outcomes in context of various sociodemographic variables.

Results: Psychiatric consequences of $\mathrm{SCl}$ were reflected in a $41 \%$ prevalence of depression. Thirty-six percent $\left(R^{2}=0.36\right)$ of the variance in $\mathrm{BDI}-\mathrm{II}$ scores $(F(5,55)=6.07, P<0.001)$ was explained by the regression model. Functional impairment $(\beta=0.54$, $t(55)=4.73, P<0.001)$ and perceived benefit through $S / R$ activities $(\beta=-0.31, t(55)=-2.55, P<0.05)$ emerged as the strongest predictors for depression severity.

Conclusions: Perceived functional impairment in work, social and family domains predicted depressive symptomatology among $\mathrm{SCl}$ inpatients in Sri Lanka, while perceived benefit through S/R protected against depression. The findings emphasize the need for rehabilitative programming to support patients' S/R activities and mental wellbeing, promoting reintegration into their community roles. Spinal Cord (2016) 54, 1158-1163; doi:10.1038/sc.2016.56; published online 3 May 2016

\section{INTRODUCTION}

Traumatic spinal cord injury (SCI) is a debilitating condition with significant impact on the patient's psychological state. A variety of factors related to patients' SCI experiences such as pain, medication, isolation, medical complications, altered body image and postinjury cognitive deficits may contribute to psychological morbidity, which in turn may negatively impact coping and quality of rehabilitation. ${ }^{1}$ Within Western societies, depression is a well-documented psychiatric complication of SCI. Between 20 and $45 \%$ of patients experience depression after their injury, and it is estimated that patients with SCI have a four to five times higher rate of suicide compared with age-matched population samples. ${ }^{1-4}$ In low- and middle-income countries, however, the prevalence of depression in patients with SCI is not well characterized. This must be rectified, as morbidity and mortality associated with SCI in developing countries remains disproportionately high. ${ }^{5}$ The World Health Organization reports that, in addition to carrying high individual and societal costs, SCI causes individuals to be two to five times more likely to die prematurely, with worse survival rates if these individuals reside in low- and middle-income countries. ${ }^{6}$ In Sri Lanka, a low-income country with a population of $\sim 20$ million, the Sri Lankan Spinal Cord
Network estimates that 2000 Sri Lankans are inflicted by traumatic SCI every year. ${ }^{7}$ This incidence, which is predicted by the Sri Lankan Spinal Cord Network to rise because of increased road traffic and industrial accidents, ${ }^{7}$ has implications for economic burden and patient suffering.

Currently, there is a lack of existing literature on psychosocial experiences of Sri Lankan patients with SCI. To address this knowledge gap, this research study aimed to explore psychiatric morbidity and coping mechanisms in a sample of Sri Lankan patients with SCI. In the exploratory phase of this study, focus groups were conducted to understand how patients perceived the impact of their injury and what coping mechanisms they actively used. Limitations of activities of daily living, fear of burdening family members, fragmentation of relational ties and inability to generate income and fulfill social roles emerged as patients' greatest concerns. Furthermore, patients frequently and almost unanimously reported that religious or spiritual practices aided them in confronting challenges posed by their injury. ${ }^{8}$

Based on qualitatively identified psychosocial concerns associated with SCI and the strong recognition of religious practice as a coping mechanism in the Sri Lankan patient population, the quantitative aspect of this study was designed to assess specific potential predictors

${ }^{1}$ Faculty of Medicine, University of Toronto, Toronto, ON, Canada; ${ }^{2}$ Department of Psychiatry, Faculty of Medicine, University of Kelaniya, Ragama, Sri Lanka; ${ }^{3}$ Division of Mood and Anxiety Disorders, Centre for Addiction and Mental Health (CAMH), Toronto, ON, Canada and ${ }^{4}$ Department of Psychiatry, University of Toronto, Toronto, ON, Canada

${ }^{5}$ These authors contributed equally to this work.

Correspondence: S Xue, Faculty of Medicine, University of Toronto, 3944 Selkirk Place, Mississauga, ON, Canada L5L 3L5.

E-mail: s.xue@mail.utoronto.ca

Received 21 July 2015; revised 14 March 2016; accepted 19 March 2016; published online 3 May 2016 
of depression. It was hypothesized that patients perceiving greater functional impairment in various life domains would be more likely to suffer from depression and that patients who identified greater benefit from spirituality/religiosity (S/R) would be less likely to suffer from depression. This paper presents the results of the quantitative analyses.

\section{MATERIALS AND METHODS \\ Setting}

Situated $\sim 20 \mathrm{~km}$ north of Colombo in the Western Province, the town of Ragama is home to the Faculty of Medicine of the University of Kelaniya and the Ragama Rheumatology and Rehabilitation Hospital. The Ragama Rehabilitation and Rehabilitation Hospital accommodates 256 in-patient beds and presently serves as the leading referral rehabilitation facility for persons living with disabilities in the country. It sees the highest number of patients with SCI in Sri Lanka at any given time.

Approval of this study was obtained from the Ethical Review Committee of University of Kelaniya and the Director of Ragama Rheumatology and Rehabilitation Hospital in Ragama, Sri Lanka.

\section{Sampling}

Participant recruitment for this study was conducted through screening of medical records at the Ragama Rheumatology and Rehabilitation Hospital. Using a purposive sampling strategy, in-patient records were screened against inclusion criteria, which included a diagnosis of SCI from a traumatic cause, fluency in Sinhala and an age of 18 years or above. Patients fitting the inclusion criteria were identified on a rolling basis as they were admitted to hospital between June and July 2014. All consecutive, consenting patients were included in data collection and analysis.

\section{Instruments}

Sociodemographic data and SCI-relevant medical history was collected from each participant. To assess dimensions of depression, objectively and subjectively defined functional impairment and S/R, respectively, the Beck Depression Inventory II (BDI-II), Spinal Cord Independence Measure III (SCIM-III), Sheehan Disability Scale (SDS) and Benefit through Religiosity/Spirituality Scale (BENEFIT) were administered. The four instruments were chosen for their applicability to a population with chronic disability, their suitability of use in Sri Lankan or other multicultural contexts, and their relative brevity. All four instruments are self-report scales, and medical residents at the Department of Psychiatry with experience in questionnaire administration assisted persons with impaired physical ability in completing the measures by reading aloud questionnaire items and noting participants' selected answers.

The BDI-II is a 21-item measure of depressive symptomatology. Each item on the BDI-II is rated on a four-point scale ranging from 0 to 3; values indicate increasing severity in a particular symptom of depression in accordance with the DSM-IV. Summed ratings yield a total score indicative of either normal mood fluctuations, mild mood disturbance, borderline clinical depression, moderate depression, severe depression or extreme depression. ${ }^{9}$ The BDI-II has been widely used in rehabilitation settings in low- and middle-income countries, and has been translated into Sinhala and validated in Sri Lanka. ${ }^{10,11}$

The SCIM-III is specifically designed for patients with spinal cord lesions, and is currently the only comprehensive measure of ability among this population. The 17-item scale assesses a patient's physical ability to perform daily tasks in three domains: care, respiration and sphincter management, and mobility. The total score ranges from 0 to 100 , with higher scores indicating better task performance or independence. The SCIM-III was formulated based on the need to address intercultural biases and was found to produce high reliability, internal consistency and external validity in SCI-sustaining patient samples from three continents. ${ }^{12}$ The SCIM-III was previously used in Sri Lanka to assess functional outcomes of patients admitted to a Médecins Sans Frontières rehabilitation program during the civil conflict in 2009.13

The SDS is a three-item questionnaire that assesses the degree of functional impairment in three interrelated life domains: work/school, social life and family life/home responsibilities. The SDS measures respondents' self-perceived extent of life disruptions due to symptomatology, whereas the SCIM assesses the severity of symptomatology itself. ${ }^{14}$ The SDS has been translated into Sinhala and is routinely used by the Faculty of Medicine of the University of Kelaniya in its psychiatric consultations. ${ }^{15}$ The SDS has also previously been implemented in an epidemiological study of the Sri Lankan population affected by the 2004 tsunami. 16

The BENEFIT is a 6-item questionnaire that measures perceived beneficial effects of S/R in context of patients' life concerns. The BENEFIT was developed in response to the need for a compact measure to better understand how $S / R$ affects health in different populations, different religious groups and different circumstances. The instrument, which is scored on a scale of 0 to 4 for each item, assesses extent of disagreement or agreement for six unique statements (Table 2). Higher scores for each statement indicate greater perceived benefit through S/R. The BENEFIT was validated in a sample of patients $(N=371)$ with chronic, disabling conditions and was found to have a high Cronbach's $\alpha$ (0.922) ${ }^{17}$ For the purposes of this study, the BENEFIT was iteratively translated from English to Sinhala, then back-translated by two independent bilingual staff. Discrepancies were resolved through consultation with psychiatrists at the University of Kelaniya to achieve a consensus final version.

\section{Data analysis}

Descriptive statistics were used to summarize sociodemographic data and injury characteristics, as well as responses to the validated measures. Planned comparisons using $\chi^{2}$ test and independent samples $t$-test were initially used to examine whether the degree of physical dependence, as indicated by the degree of paralysis and SCIM-III scores, was significantly different between clinically depressed and non-depressed individuals. To examine whether selfperceived functional impairment and S/R activities would predict psychiatric outcomes while accounting for various sociodemographic variables, a one-step linear regression model on the BDI-II score was developed. The model incorporated SDS and BENEFIT scores, as well as age, marital status and income level before SCI as independent variables. Sex and education were not included in the model because of the largely unequal distribution between genders and education levels within the study sample.

\section{RESULTS}

Of the sample population, 62 patients met inclusion criteria. One patient chose not to participate, and written informed consent to participate in the study was obtained from 61 individuals, of whom 55 were males and 6 were females. Detailed sociodemographic descriptions and injury-related characteristics were obtained (Table 1). Participants' ages ranged from 18 to 68 years, with a mean age of 39.5 years and a median age of 37 years(s.d. $=14.7)$. Approximately $68 \%$ of the study sample was married, and $52 \%$ had one or more children. Educational achievement for the majority (84\%) was a high school diploma, and a similar proportion (80\%) reported earning an income of $<$ Rs 5000 LKR (Sri Lankan Rupee) to Rs 20000 LKR monthly ( US \$40-150) before injury. Approximately $50 \%$ of the participants were referred from the Western Province; the remaining half of the study sample consisted of patients from across seven other provinces. Ethnic and religious identification showed $90 \%$ as Sinhalese and $85 \%$ as Buddhist. Common causes of SCI included falls from height $(49 \%)$ and road traffic accidents (39\%). Following the cause of injury, $66 \%$ of the study sample sustained tetraplegia, and $34 \%$ sustained paraplegia. None reported existing psychiatric diagnoses before hospital admission nor any family history of psychiatric illness.

\section{Psychiatric symptoms and functional impairment}

Psychiatric consequences of SCI were reflected in a $41 \%$ prevalence of clinically significant depressive symptoms as measured by the BDI-II. Of the depressed individuals, eight scored between 17 and 20 (borderline clinical depression), eight scored between 21 and 30 
Table 1 Participant demographic and injury characteristics

\begin{tabular}{|c|c|c|}
\hline Descriptor & $\mathrm{n}$ & $\%$ \\
\hline \multicolumn{3}{|l|}{ Gender } \\
\hline Male & 55 & 90.2 \\
\hline Female & 6 & 9.8 \\
\hline \multicolumn{3}{|l|}{ Marital status } \\
\hline Married & 41 & 67.2 \\
\hline Unmarried & 20 & 32.8 \\
\hline \multicolumn{3}{|l|}{ Education } \\
\hline High school or less & 51 & 83.6 \\
\hline Bachelor's degree & 9 & 14.8 \\
\hline Postgraduate degree & 1 & 1.6 \\
\hline \multicolumn{3}{|l|}{ Income before injury } \\
\hline$<$ Rs 5000 LKR & 23 & 37.7 \\
\hline Rs 5000-20000 LKR & 26 & 42.6 \\
\hline > Rs 20000 LKR & 12 & 19.7 \\
\hline \multicolumn{3}{|l|}{ Province } \\
\hline Western & 31 & 50.8 \\
\hline North Western & 13 & 21.3 \\
\hline Sabaragamuwa & 5 & 8.2 \\
\hline Uva & 4 & 6.6 \\
\hline Other & 8 & 13.1 \\
\hline \multicolumn{3}{|l|}{ Ethnicity } \\
\hline Sinhalese & 55 & 90.2 \\
\hline Tamil & 4 & 6.6 \\
\hline Moor & 2 & 3.3 \\
\hline \multicolumn{3}{|l|}{ Religion } \\
\hline Buddhist & 52 & 85.2 \\
\hline Hindu & 4 & 6.6 \\
\hline Catholic & 3 & 4.9 \\
\hline Muslim & 2 & 3.3 \\
\hline \multicolumn{3}{|l|}{ Cause of injury } \\
\hline Fall from height & 30 & 49.2 \\
\hline Road traffic accident & 24 & 39.3 \\
\hline Fallen object & 3 & 4.9 \\
\hline Violence and assault & 2 & 3.3 \\
\hline War & 2 & 3.3 \\
\hline \multicolumn{3}{|l|}{ Degree of paralysis } \\
\hline Tetraplegia & 40 & 65.6 \\
\hline Paraplegia & 21 & 34.4 \\
\hline
\end{tabular}

Abbreviation: LKR, Sri Lankan Rupee.

(moderate depression) and nine scored above 30 (severe or extreme depression). Among all participants, SCIM-III measurements showed a mean of $47($ s.d. $=21.7)$ on a scale from 0 to 100 , indicating moderate level of physical limitations, and SDS measurements revealed a mean of 22 (s.d.=9.0), indicating marked self-perceived functional impairment. SCIM-III scores were not found to differ significantly between depressed and non-depressed groups $t(59)=1.50, P>0.05$ nor was there any difference between depressed and non-depressed groups in the degree of paralysis, whether paraplegic or tetraplegic $\chi^{2}(1, N=61)=0.11, P>0.05$.

\section{$S / R$ practices and religious beliefs}

Respondents frequently perceived benefits through S/R activities, as demonstrated by the high mean BENEFIT score of 21 (s.d.=3.2). Strong agreement was expressed for all six items of the scale, with a majority of respondents agreeing that the item statement 'definitely applies' to their $\mathrm{S} / \mathrm{R}$ experiences and giving a mean score of at least 3.4 (s.d. $=0.8$ ) out of 4 for each item. Descriptive statistics for the BENEFIT items are provided in Table 2.

\section{Prediction of depression}

Linear regression analyses were used to test predictors of depression severity (Table 3$)$. Approximately $36 \%\left(R^{2}=0.36\right)$ of the variance in BDI-II scores $(\mathrm{F}(5,55)=6.07, P<0.001)$ was explained by the regression model. Self-perceived functional disability as measured by SDS emerged as the strongest predictor of depression symptom severity. Self-perceived benefit through S/R activities as measured by BENEFIT accounted for the second largest proportion of variance, demonstrating an inverse relationship between $S / R$ activities and depressive symptomatology.

\section{DISCUSSION}

\section{Prevalence of depressive symptoms}

Clinically significant depressive symptoms were found in $41 \%$ of our patient sample, with $28 \%$ suffering from either moderate or severe depression. Through disease modeling based on a systematic review of epidemiological data, Ferrari et al. ${ }^{18}$ found the 2010 age-standardized point prevalence for major depressive disorder in Sri Lanka to be $4.73 \%$, with a $95 \%$ uncertainty interval of $3.19-6.66 \%$. The results of our study reflect a much higher prevalence of depressive symptoms among patients with traumatic SCI compared with this most recent estimate for the general Sri Lankan population. Overall, the finding that traumatic SCI puts individuals at risk for depression is expected and in keeping with findings from the West, where a review of literature on post-SCI psychological morbidity during the first 6-8 months following injury estimates the risk of depressive disorder to be 20 to $40 \% .^{19}$

\section{Functional independence and self-perceived impairment with relation to depression}

There was no significant difference in SCIM-III scores or type of paralysis between patients with clinically significant depressive symptoms and those without. This is consistent with previous research, which has similarly found that, in general, there is no association between depression severity and injury characteristics such as lesion level or lesion completeness. In particular, it has been previously concluded that the incidence of depression is unaffected by whether patients are paraplegic or tetraplegic. ${ }^{20}$ More recent studies of SCI corroborate the finding that injury characteristics such as lesion level, lesion completeness and functional impairment are not associated with depression severity. ${ }^{21-23}$ However, a few authors have found a relationship between lower functional independence and depression, and findings in this area seem to remain unclear. ${ }^{24,25}$ Of note, we chose not to include characteristics such as level and injury completeness in our regression model as our study did not hypothesize that physical injury characteristics would have an impact on or relation with depression given the past literature. Rather, we were interested in the predicative value of psychosocial characteristics such as perceived impairment in family, work/school and social life.

In contrast to findings regarding the lack of relationship between degree of physical dependence and severity of depression, SDS score was the strongest predictor of depression severity in our patient 
sample. This is in keeping with past research in the Sri Lankan setting, which has also found that depression scores correlate with all three impairment subscales (extent of work, family and social disruption) on the SDS. ${ }^{16}$ While the SCIM-III is a measurement tool used by clinicians, the SDS is a self-report tool, and unique patient factors are thus more likely to influence responses. SDS may be related to depression because of a variety of modulating factors, including, but not limited to, social support, adaptation strategies and personal resilience. Patients' personal appraisals of impairment within various life domains influence responses on the SDS, and could also modulate patients' rehabilitation experience and psychological sequelae. Indeed, appraisals beginning in early stages of rehabilitation have been associated with psychological wellbeing in the SCI population, and coping early after injury has been found to be significantly related to quality of life outcomes up to 2 years postinjury. ${ }^{26,27}$

\section{Religiosity with relation to depression}

All patients in our sample identified with a particular religion, and a mean score of at least 3.4 out of 4 was given for each individual BENEFIT item, indicating high perceived benefit through S/R. The four main religions observed in Sri Lanka were represented in this study, with $85.5 \%$ of respondents identifying as Buddhists. These numbers are fairly representative of the general patient population, as nearly all members Sri Lanka's population observe a certain religion, with over $70 \%$ of Sri Lankans observing Buddhism. ${ }^{28}$

BENEFIT scores were found to inversely predict depressive symptoms in our patient population, the reasons for which may be explained by the use of $S / R$ practices as a method for coping. Past literature investigating adjustment in individuals with chronic disabilities has found that spirituality can assist patients in coping with life changes, ${ }^{29-33}$ and a literature review including 724 quantitative studies found that a majority of studies report religion to be significantly associated with better mental health and greater social support. ${ }^{34}$ With specific regard to SCI patients, Marini et al. ${ }^{35}$ found that $S / R$ practices and a belief in God or a Spiritual Power help patients cope with the effects of their injury and provide them with a sense of purpose in life. White et al. ${ }^{23}$ further found significant correlations between spirituality, resilience, satisfaction in life and reduced depressive symptomatology in SCI patients, and Matheis et al. ${ }^{36}$ found that $98.7 \%$ of SCI patients in their sample reported using spiritual-based coping to the effect of greater perceived quality of life.

Our own qualitative work using focus groups revealed $S / R$ practices to be mechanisms by which participants confront personal challenges following SCI. ${ }^{8}$ Participants in our patient sample relied on S/R practices for comfort and consolation, and some believed that their $\mathrm{S} / \mathrm{R}$ practices assisted them in improving their health condition. While our qualitative findings elucidate the importance of $S / R$ towards our patient sample's overall coping, our quantitative findings specifically show that depressive symptoms in our patient population are inversely predicted by perceived benefit through $\mathrm{S} / \mathrm{R}$.

In the World Health Organization framework for measuring health and disability, spirituality is acknowledged as a contributor to wellbeing. ${ }^{37}$ It has been strongly suggested that, given the extent to which S/R practices help patients with disabilities cope and establish meaning in their lives, rehabilitation professionals adopt practical strategies to enhance religious coping. ${ }^{32,38}$ Koenig ${ }^{38,39}$ suggests that rehabilitation professionals ask particular questions around spiritual belief and spiritual needs during the taking of a spiritual history; such a history inquires about the role of $S / R$ with regard to a patient's understandings of their injury and aims to understand the use of $S / R$ for subsequent coping. In addition, Johnstone et al. ${ }^{32}$ advise that 
Table 3 Prediction of depression: Summary of linear regression analyses testing predictors of depression severity as measured by Beck Depression Inventory-II

\begin{tabular}{lccc}
\hline Predictor & \multicolumn{1}{c}{$B(95 \% \mathrm{Cl})$} & S.e. B & $\beta$ \\
\hline Age & $0.11(-0.07$ to 0.29$)$ & 0.09 & 0.15 \\
Marital status & $-4.97(-10.80$ to 0.86$)$ & 2.91 & -0.22 \\
Income & $-0.48(-1.89$ to 0.93$)$ & 0.70 & -0.08 \\
SDS & $0.65(0.38$ to 0.93$)$ & 0.14 & $0.54^{* *}$ \\
BENEFIT & $-1.05(-1.87$ to 0.22$)$ & 0.41 & $-0.31^{*}$ \\
\hline
\end{tabular}

Abbreviations: BENEFIT, Benefit through Religiosity/Spirituality Scale; $\mathrm{Cl}$, confidence interval; SDS, Sheehan Disability Scale.

$* P<0.05 ; * * P<0.0001$.

rehabilitation professionals address religious issues with patients in an initial interview, establish an early understanding of their patients' worldviews and the possible effect of these views on adherence to treatment, and recommend the use of external religious support systems, when appropriate, to facilitate community reintegration. ${ }^{32}$ Given the prevalence of depressive symptomatology in our patient sample and the finding of religiosity as an inverse predictor of depression severity, there may be benefit for such recommended measures to be adopted in the Sri Lankan setting.

There are limitations to this study that must be considered. First, we acknowledge that there is criticism that using the BDI-II in SCI populations may falsely elevate estimates of depression based on somatic symptom-focused questionnaire items. ${ }^{40}$ However, the BDI has been shown to be fairly reliable in patients with traumatic SCI, and remains one of the most commonly used tools for this patient population. ${ }^{24,41}$ We deliberately chose the instrument due to its prior use in similar patient populations as well as geographic settings, and chose the more conservative cutoff of 17 to maximize specificity. Second, females were largely under-represented in our study sample given that the Ragama Rheumatology and Rehabilitation Hospital sees much fewer females as opposed to males sustaining traumatic SCI, in whom such injuries are more common. Thus, the results of this study may not be generalizable to females with traumatic SCI. Last, the majority of our sample consisted of individuals with low-income and a high school diploma education, which could be an important contributor to the detected prevalence of depressive symptoms. We recommend future work with larger, more diverse samples to better understand how socioeconomic status impacts appraisal, coping and depressive symptomatology. Our sample was further unique in that the patients had access to in-hospital practical rehabilitative programs; examining depressive symptomatology in patients with SCI living in rural communities, who may not have such instrumental and informational support, would be of further interest.

\section{CONCLUSIONS}

This cross-sectional study found that perceived functional impairment in work, social and family domains predicted depressive symptomatology among traumatic SCI inpatients in Sri Lanka while perceived benefit through $\mathrm{S} / \mathrm{R}$ protected against depression. The high prevalence of depressive symptoms in our study sample emphasizes the need for culturally sensitive, practical rehabilitative programming to focus on patients' psychological wellbeing. S/R practices should be respected as aids to rehabilitation and future therapeutic efforts should assist patients to regain functional independence such that they may reintegrate into their work, social and family lives. A larger study would be useful to verify and extend these results, including the value of $S / R$ practices as an aid to rehabilitation and reintegration into the community.

\section{DATA ARCHIVING}

There were no data to deposit.

\section{CONFLICT OF INTEREST}

The authors declare no conflict of interest.

\section{ACKNOWLEDGEMENTS}

We extend our sincere gratitude to all the staff at the Ragama Rheumatology and Rehabilitation Hospital. We also thank Dr Martha McKay and Tadeu

Ferreira for their guidance on statistical analyses.

1 North N. The psychological effects of spinal cord injury: a review. Spinal Cord 1999; 37: 671-679.

2 Kirshblum SC, Priebe MM, Ho CH, Scelza WM, Chiodo AE, Wuermser LA. Spinal cord injury medicine: 3 - Rehabilitation phase after acute spinal cord injury. Arch Phys Med Rehabil 2007; 88: S62-S70.

3 Hagen EM, Lie SA, Rekand T, Gilhus NE, Gronning M. Mortality after traumatic spinal cord injury: 50 years of follow-up. J Neurol Neurosurg Psychiatry 2010; 81: 368-373.

4 DeVivo MJ, Black K, Richards JS, Stover S. Suicide following spinal cord injury. Spinal Cord 1991; 29: 620-627.

5 Burns AS, O'Connell C. The challenge of spinal cord injury care in the developing world. J Spinal Cord Med 2012; 35: 3-8.

6 Spinal Cord Injury: World Health Organization [Internet]; 2013. Available at http://www. who.int/mediacentre/factsheets/fs384/en/(last accessed 15 December 2014).

7 Welcome to SLSCoN Official Website Sri Lanka Spinal Cord Network [Internet]; 2014. Available at http://slspinalcord.org/ (last accessed 14 December 2014).

8 Arya S, Xue S, Embuldeniya A, Narammalage H, da Silva T, Williams S et al. Coping strategies used by traumatic spinal cord injury patients in Sri Lanka: a focus group study. Disabil Rehabil (e-pub ahead of print 5 January 2016; doi: 10.3109/ 09638288.2015.1111433).

9 Dozois DJ, Dobson KS, Ahnberg JL. A psychometric evaluation of the Beck Depression Inventory-II. Psychol Assess 1998; 10: 83.

10 Van Hemert DA, Van De Vijver FJ, Poortinga YH. The Beck Depression Inventory as a measure of subjective well-being: a cross-national study. J Happiness Stud 2002; 3: 257-286.

11 McColl H, Higson-Smith C, Gjerding S, Omar MH, Rahman BA, Hamed M et al. Research rehabilitation of torture survivors in five countries: common themes and challenges. Int J Ment Health Syst 2010; 4: 16.

12 Catz A, Itzkovich M, Tesio L, Biering-Sorensen F, Weeks C, Laramee M et al. A multicenter international study on the Spinal Cord Independence Measure, version III: Rasch psychometric validation. Spinal Cord 2007; 45: 275-291.

13 Armstrong JC, Nichols BE, Wilson JM, Cosico RA, Shanks L. Spinal cord injury in the emergency context: review of program outcomes of a spinal cord injury rehabilitation program in Sri Lanka. Conflict Health 2014; 8: 4.

14 Leon A, Shear MK, Portera L, Klerman G. Assessing impairment in patients with panic disorder: the Sheehan Disability Scale. Soc Psychiatry Psychiatr Epidemiol 1992; 27: 78-82.

15 Suraweera C, Hanwella R, Sivayokan S, de Silva V. Rating Scales validated for Sri Lankan populations. Sri Lanka J Psychiatry 2013; 4: 16-24.

16 Hollifield M, Hewage C, Gunawardena CN, Kodituwakku P, Bopagoda K, Weerarathnege K. Symptoms and coping in Sri Lanka 20-21 months after the 2004 tsunami. Br J Psychiatry 2008; 192: 39-44.

17 Büssing A, Koenig HG. The Benefit through spirituality/religiosity scale-a 6-item measure for use in health outcome studies. Int J Psychiatry Med 2008; 38 : 493-506.

18 Ferrari AJ, Charlson FJ, Norman RE, Patten SB, Freedman G, Murray CJ et al. Burden of depressive disorders by country, sex, age, and year: findings from the global burden of disease study 2010. PLoS Med 2013; 10: e1001547.

19 Craig A, Tran Y, Middleton J. Psychological morbidity and spinal cord injury: a systematic review. Spinal Cord 2009; 47: 108-114.

20 Frank RG, Elliott TR, Corcoran JR, Wonderlich SA. Depression after spinal cord injury: is it necessary? Clin Psychol Rev 1987; 7: 611-630.

21 Fuhrer MJ, Rintala DH, Hart KA, Clearman R, Young ME. Depressive symptomatology in persons with spinal cord injury who reside in the community. Arch Phys Med Rehabil 1993; 74: 255-260.

22 Shin JC, Goo HR, Yu SJ, Kim DH, Yoon SY. Depression and quality of life in patients within the first 6 months after the spinal cord injury. Ann Rehabil Med 2012; 36: 119-125.

23 White B, Driver S, Warren AM. Resilience and indicators of adjustment during rehabilitation from a spinal cord injury. Rehabil Psychol 2010; 55: 23.

24 Kennedy P, Rogers BA. Anxiety and depression after spinal cord injury: a longitudinal analysis. Arch Phys Med Rehabil 2000; 81: 932-937. 
25 Burnett D, Kolakowsky-Hayner S, White J, Cifu D. Impact of minority status following traumatic spinal cord injury. NeuroRehabilitation 2002; 17: 187.

26 Kennedy P, Lude P, Elfstrom ML, Smithson E. Cognitive appraisals, coping and quality of life outcomes: a multi-centre study of spinal cord injury rehabilitation. Spinal Cord 2010; 48: 762-769.

27 Kennedy $\mathrm{P}$, Lude $\mathrm{P}$, Elfstrom ML, Smithson E. Appraisals, coping and adjustment pre and post SCl rehabilitation: a 2-year follow-up study. Spinal cord 2012; 50: 112-118.

28 Census of Population and Housing of Sri Lanka [Internet]; 2012. Available at http://tinyurl.com/q7tnwko (last accessed 10 February 2015).

29 Connor KM, Davidson JR. Development of a new resilience scale: the Connor-Davidson resilience scale (CD-RISC). Depress Anxiety 2003; 18: 76-82.

30 Connor KM, Davidson JR, Lee LC. Spirituality, resilience, and anger in survivors of violent trauma: a community survey. J Trauma Stress 2003; 16: 487-494.

31 Hodges S. Mental health, depression, and dimensions of spirituality and religion. J Adult Dev 2002; 9: 109-115.

32 Johnstone B, Glass BA, Oliver RE. Religion and disability: clinical, research and training considerations for rehabilitation professionals. Disabil Rehabil 2007; 29: 1153-1163.

33 Richardson GE. The metatheory of resilience and resiliency. J Clin Psychol 2002; 58: 307-321.
34 Koenig H, King D, Carson VB. Handbook of Religion and Health. Oxford University Press: Cambridge, UK, 2012.

35 Marini I, Glover-Graf NM. Religiosity and spirituality among persons with spina cord injury: attitudes, beliefs, and practices. Rehabil Counsel Bull 2011; 54: 82-92.

36 Matheis EN, Tulsky DS, Matheis RJ. The relation between spirituality and quality of life among individuals with spinal cord injury. Rehabil Psychol 2006; 51 : 265.

37 World Health Organization. International Classification of Functioning, Disability and Health. World Health Organization: Geneva, Switzerland, 2001.

38 Koenig HG. An 83-year-old woman with chronic illness and strong religious beliefs. JAMA 2002; 288: 487-493.

39 Koenig HG. Religion, spirituality, and medicine: research findings and implications for clinical practice. Southern Med J 2004; 97: 1194-1200.

40 Jacob KS, Zachariah K, Bhattacharji S. Depression in individuals with spinal cord injury: methodological issues. Spinal Cord 1995; 33: 377-380.

41 Judd FK, Brown DJ, Burrows GD. Depression, disease and disability: application to patients with traumatic spinal cord injury. Spinal Cord 1991; 29: 91-96. 